\title{
Rechargeable Li-Air Batteries with Carbonate-Based Liquid Electrolytes
}

\author{
Fuminori Mizuno,* Shinji NaKanishi, Yukinari Kotani, Shoji Yokoishi, and Hideki Iba
}

\author{
Battery Research Division, Toyota Motor Corporation Higashifuji Technical Center (1200 Mishuku, Susono, \\ Shizuoka 410-1193, Japan)
}

\author{
Received November 30, 2009 ; Accepted January 12, 2010
}

\begin{abstract}
Rechargeable Li-air battery is a candidate for post Li-ion battery with high energy density. In this paper, the rechargeability of Li-air battery over 100 cycles was confirmed and its capacity retention over $60 \%$ was achieved. Nevertheless, a large voltage gap between the discharge-charge profiles was observed. Here, a discharged product formed on a cathode was investigated by TEM observation and FT-IR spectroscopy. It was found that the main product formed in discharge was not an ideal compound, $\mathrm{Li}_{2} \mathrm{O}_{2}$, but was carbonate species issued from the decomposition of carbonate-based electrolyte solvent.
\end{abstract}

Key Words : Li-Air Battery, Rechargeablility, Air Cathode, $\mathrm{Li}_{2} \mathrm{O}_{2}$

\section{Introduction}

Hybrid vehicles such as the "PRIUS" are of considerable practical concern from viewpoints of the global warming and the shortage of oil resources. PRIUS has both gasoline engine and Ni-MH secondary battery as power sources, resulting in high fuel efficiency with high driving performance. Improvement of the secondary batteries would greatly contribute to the realization of low carbon society in the future.

In order to drive long distance over $500 \mathrm{~km}$ by charging only 1 time, secondary batteries with high volumetric energy density over $2000 \mathrm{Wh} \mathrm{L}^{-1}$ are highly desired. At present, the utilization of Li-ion batteries into Plug-in hybrid and pure electric vehicles has attracted a growing interest, since Li-ion batteries can achieve higher energy density than the Ni-MH ones. However, the volumetric energy density of commercialized Li-ion batteries reaches a limit of $1000 \mathrm{Wh} \mathrm{L}^{-1}$. Thus, the research on next generation rechargeable battery with much higher energy density is strongly required.

One of the candidates is the metal-air battery. ${ }^{1-11)}$ Metal-air battery is generally composed of a metal anode, a liquid-based electrolyte and an air cathode with catalyst-loaded carbon under an oxygen gas atmosphere. Oxygen gas as cathode fuel is supplied from outside of the battery, and therefore most of the battery is occupied by metal anode, which led to the improvement of volumetric energy density. $\mathrm{Zn}$-air battery with flat voltage profile and long operating time is originally used as a primary battery in hearing aids. One of the reasons not to use the $\mathrm{Zn}$-air battery as a secondary one is that short circuits could easily happen due to $\mathrm{Zn}$ dendrite formation on the surface of anode during charge. ${ }^{2)}$

Research on Li-air battery has been recently reported by many researchers. ${ }^{3-11)}$ Abraham's group first reported that the cell with a gel polymer electrolyte worked as a secondary battery. ${ }^{3)}$ Since then, a lot of cell performances on carbon, ${ }^{8-10)}$ catalyst $^{6,7)}$ and electrolyte ${ }^{4,5,11)}$ have been studied in detail. On the contrary, few studies on the rechargeability of Li-air cell have been published. Bruce's group first demonstrated the rechargeability of Li-air cell with a carbonate-based organic electrolyte for 50 cycles. ${ }^{6}$ $60 \%$ capacity retention was achieved after 50 cycles. However, the discharge and charge voltages were reported to be respectively $2.6 \mathrm{~V}$ and $4.0 \mathrm{~V}$, and the voltage gap was therefore about $1.4 \mathrm{~V}$. This large voltage gap results in a lowering of energy efficiency although the battery can theoretically store much more energy.

In this paper, we demonstrated the rechargeability of Li-air cell over 100 cycles. Furthermore, we focused on the analysis of discharged products, which are the source of a rechargeable system, to understand the reasons for large voltage gap between discharge and charge profiles. The discharged products were examined by Transmission Electron Microscope (TEM) observation and Fourier Transform Infrared (FT-IR) spectroscopy.

\section{Experimental}

Two different types of air cathodes were used for cell performances and analyses and are described as follows. To check the cell performances, air cathodes were prepared by coating acetone slurries of Super P carbon black, $\mathrm{MnO}_{2}$ powder used as a catalyst and Kynar2801 binder on a carbon paper. The weight ratio of components was respectively $25: 42: 33$ as indicated in the published paper. ${ }^{4}$ The obtained cathode was dried at $120^{\circ} \mathrm{C}$ overnight under vacuum. For analyses, the other air cathodes composed of Ketjen Black, $\mathrm{MnO}_{2}$ catalyst and PTFE binder with $80: 10: 10$ in weight ratio were used. The mixture was pressed by roll pressing into a pellet which was dried at $120^{\circ} \mathrm{C}$ overnight under vacuum.

Battery grade LiTFSI/PC solution was used as a liquid electrolyte. LiTFSI and PC are respectively abbreviation for propylene carbonate and lithium bis-trifluoromethansulfonylimide. The concentration of LiTFSI salt was $1 \mathrm{M}$ and the content of water in the electrolyte was below $20 \mathrm{ppm}$. Lithium metal with $0.25 \mathrm{~mm}$ in thickness was used as an anode. Stainless steal disk and nickel 
mesh were used as a current collector of anode and cathode, respectively. In a dry glove box filled with Argon gas, these parts were set in our custom-made cell where the distance between anode and cathode is $5 \mathrm{~mm}$. Then, the cell was put in a gas tight glass container. After assembling of the cell, Argon gas was completely replaced with pure oxygen gas $(99.99 \%$ purity). The cell was kept for $3 \mathrm{~h}$ at room temperature to dissolve oxygen gas into the liquid electrolyte. The cell was pre-cycled for 5 times at room temperature using charge-discharge machine (Nagano, BTS2004H) to enhance the wettability of liquid electrolyte against air cathode. Current density was $0.02 \mathrm{~mA} \mathrm{~cm}^{-2}$ and the cut-off voltages on discharge and charge were $2.0 \mathrm{~V}$ and $4.3 \mathrm{~V}$, respectively. Finally, the cell was discharged and recharged for 100 cycles at the same condition.

The discharged cathode or discharged products were then analyzed by TEM observation and FT-IR spectroscopy. TEM images of discharged products set on a cupper grid were taken by a FE-TEM apparatus (JEM2010F, JEOL) with a working voltage of $200 \mathrm{kV}$. FT-IR spectrum of discharged cathode was recorded by a spectrometer (Magna550, ThermoFischer Sci.) with a photoacoustic apparatus. He gas was flowed under a constant rate during the measurement.

\section{Results and Discussion}

Figure 1 shows the discharge capacity of Li-air battery as a function of cycle number. The first discharge-charge curves are also shown in the inset figure. Capacity was normalized by weight of carbon in the air cathode. The first discharge capacity was $824 \mathrm{mAh} \mathrm{g}^{-1}$ and the average voltage of discharge was $2.7 \mathrm{~V}$. On recharging, two plateaus at around $3.2 \mathrm{~V}$ and $4.1 \mathrm{~V}$ were observed. The voltages of $2.7 \mathrm{~V}$ and $4.1 \mathrm{~V}$ in discharge and charge are in good agreement with the previous paper.6) The charging voltage of $3.2 \mathrm{~V}$ is very close to the theoretical potential of $\mathrm{Li}_{2} \mathrm{O}_{2}, 3.1 \mathrm{~V}$, ${ }^{3)}$ which is believed that $\mathrm{Li}_{2} \mathrm{O}_{2}$ would be partly formed in discharge. As can be seen in Fig. 1, the fabricated Li-air cell could be discharged and recharged over 100 times. Capacity retention after 100th cycle against the first cycle was over $60 \%$, which was higher than the retention reported in the previous paper. $\left.{ }^{6}\right)$ It is suggested that the air cathode supported on the carbon paper would present higher porosity than other cathodes used so far. At the 22nd, 73rd and 95th cycles, the discharge capacity suddenly increased because the cell was temporarily rested under an open circuit voltage at room temperature. During cycling, the $\mathrm{O}_{2}$ supply, especially the dissolution of $\mathrm{O}_{2}$ gas into the liquid electrolyte, might become gradually more and more difficult to do. It is presumed that a discharge capacity would be recovered by supplying of $\mathrm{O}_{2}$ gas around the air cathode. After cycling, the impedance of cell was also investigated using a Solartron 1260 frequency response analyzer. The impedance of the cathode at the initial state was about $50 \mathrm{ohms}$, while the impedance after 100 cycles was over $500 \mathrm{ohms}$. It is suggested that the increase in cathode impedance would result in the capacity fading of about $40 \%$ obtained during cycling. After disassembling of the

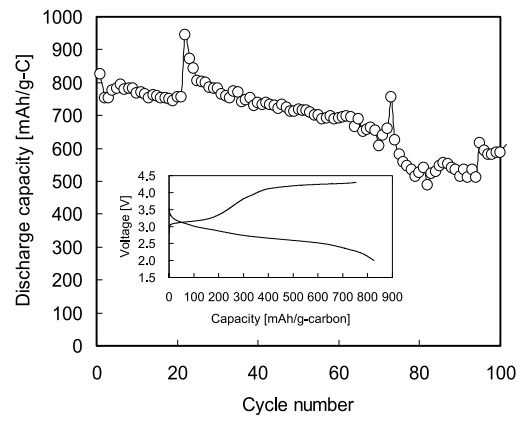

Fig. 1 Discharge capacity of Li-air battery as a function of cycle number. The first discharge-charge curves are also shown in the inset figure.

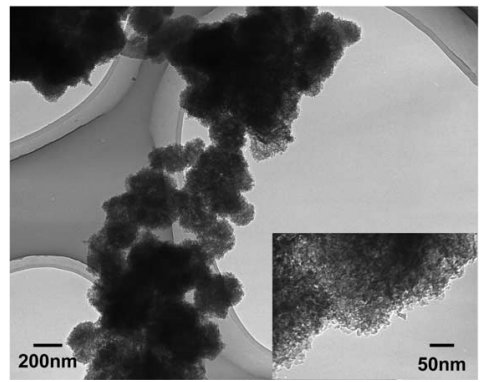

Fig. 2 TEM images of discharged products formed on the cathode surface. The magnified picture of discharged products is shown in the inset figure.

cell, the cycled cathode was collected, rinsed by diethyl carbonate (DEC, battery grade) and then dried in an Argon glove box. The cycled cathode visually contained white deposits, which are believed to be at the origin of the capacity fading.

In order to more precisely identify the composition of the white deposits, a new discharged sample was prepared for analyses. Using PTFE-based cathode, a cell was just discharged and then disassembled. After rinsing by the DEC solvent, the air cathode was dried at ambient temperature for few days in an Argon glove box. Visually observing, the rinsed air cathode color was changed from original black to white. SEM observation confirmed that discharged products were deposited on the surface of the air cathode. Figure 2 shows the TEM images of discharged products formed on the cathode surface. Granular aggregates of 200-300 nm in size were observed and closely overlapped. The magnified picture of discharged products is shown in the inset figure. The aggregate was composed of very small primary particles of around $10 \mathrm{~nm}$ diameter. From the results of EDX analysis, both signals of carbon and oxygen were observed in the discharged product, which indicates that oxide or carbonate would be formed. Other analyses such as electron energy-loss spectroscopy (EELS) and electron diffraction (ED) were also carried out. The sample was unstable under the electron beam and it was, therefore, difficult to further analyze the discharged product.

Figure 3 shows the FT-IR spectrum of discharged cathode by photoacoustic spectroscopy. Two types of compounds were observed as indicated by solid lines and arrows. Solid lines at around 1500, 1450, 1080, 870 and 


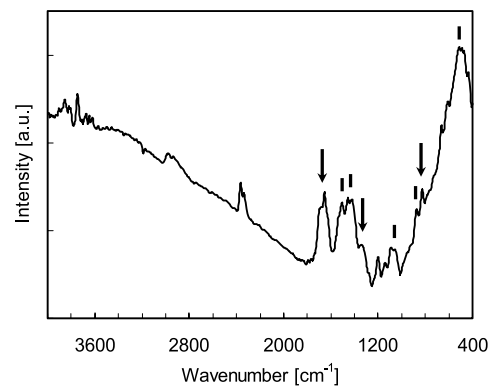

Fig. 3 FT-IR spectrum of discharged cathode by photoacoustic spectroscopy. Solid lines and arrows denote the peaks due to $\mathrm{Li}_{2} \mathrm{CO}_{3}$ and $\mathrm{RO}-(\mathrm{C}=\mathrm{O})-\mathrm{OLi}$, respectively.

$525 \mathrm{~cm}^{-1}$ denote the peaks attributed to $\mathrm{Li}_{2} \mathrm{CO}_{3}$. Furthermore, peaks at around 1650, 1360 and $825 \mathrm{~cm}^{-1}$ (indicated by arrows) were assigned to lithium alkylcarbonate, $\mathrm{RO}-(\mathrm{C}=\mathrm{O})-\mathrm{OLi}(\mathrm{R}=$ alkyl group), which is well known as one of the SEI layer compounds in the $\mathrm{Li}$ ion batteries. ${ }^{12)}$ On the other hand, the $\mathrm{Li}_{2} \mathrm{O}_{2}$ characteristic peak expected at around $550 \mathrm{~cm}^{-1}$ was not clearly observed, suggesting that either $\mathrm{Li}_{2} \mathrm{O}_{2}$ peak might be hidden in the background, or otherwise that $\mathrm{Li}_{2} \mathrm{O}_{2}$ would not be formed. The discharged product was also detected by Raman spectroscopy, which is a common technique to identify $\mathrm{Li}_{2} \mathrm{O}_{2}{ }^{3}$ ) Raman spectrum indicated that the product could not be assigned to $\mathrm{Li}_{2} \mathrm{O}_{2}$ but to carbonate species such as $\mathrm{Li}_{2} \mathrm{CO}_{3}$ and $\mathrm{R}-\mathrm{O}-(\mathrm{C}=\mathrm{O})-\mathrm{OLi}$.

Here, the results of discharged products on the air cathode will be discussed. After discharging, $\mathrm{Li}_{2} \mathrm{O}_{2}$ ideal compound was not analytically found, although $\mathrm{Li}_{2} \mathrm{O}_{2}$ is presumed to be formed in the charging profile. On the other hand, lithium carbonate $\left(\mathrm{Li}_{2} \mathrm{CO}_{3}\right)$ and lithium alkylcarbonate $(\mathrm{RO}-(\mathrm{C}=\mathrm{O})-\mathrm{OLi})$ were identified. Two reasons for the formation of these carbonate species are considered. One of the reasons is that the carbonate species might be generated by a chemical reaction of $\mathrm{Li}_{2} \mathrm{O}_{2}$ with carbonate-based electrolytes or $\mathrm{CO}_{2}$ gas including a slight amount of water. According to our preliminary study, $\mathrm{Li}_{2} \mathrm{O}_{2}$ is highly reactive against carbonate solvents and moist $\mathrm{CO}_{2}$ gas, suggesting that a part of $\mathrm{Li}_{2} \mathrm{O}_{2}$ might change into carbonate species such as $\mathrm{RO}-(\mathrm{C}=\mathrm{O})-\mathrm{OLi}$ and $\mathrm{Li}_{2} \mathrm{CO}_{3}$. The other is that the carbonate species would be formed by a decomposition of carbonate-based electrolytes such as PC at around $2.5 \mathrm{~V}$. In general, the decomposition of $\mathrm{PC}$ occurs at a lower reduction potential of $1 \mathrm{~V}$ vs. $\mathrm{Li} / \mathrm{Li}^{+}{ }^{12)}$ It is assumed that in the Li-air system, the PC solvent would be easily decomposed by $\mathrm{O}_{2}$ gas at higher reduction potential. Although the situation is different, Katayama et al. have reported the electrochemical stability of non-aqueous solvents such as ionic liquids under $\mathrm{O}_{2}$ atmosphere. ${ }^{13)} \mathrm{In}$ an ionic liquid, $\mathrm{O}_{2}$ radical as a strong nuclear agent is produced by one electron reduction, and then all of the radical is not oxidized. This implies that electrochemically formed $\mathrm{O}_{2}$ radical would not be chemically stable in the media and highly reactive against the ionic liquid. It is, thus, proposed that in the system using the carbonate-based electrolyte, $\mathrm{O}_{2}$ radical formed during discharge would attack the electrolyte solvent such as PC. The resulting decom- posed species (i.e. carbonates) would be then deposited on the surface of cathode. Finally, on charging, unidentified $\mathrm{Li}_{2} \mathrm{O}_{2}$ would be decomposed at around $3.2 \mathrm{~V}$, whereas the carbonate species must be done at higher oxidation potential over $4 \mathrm{~V}$. It is summarized that the large voltage gap shown in Fig. 1 would be caused by the formation of decomposed carbonate species in discharge. In the future, electrolytes presenting high electrochemical and chemical stability against $\mathrm{O}_{2}$ radical should be developed. On the other hand, TEM images exhibited two different morphologies of discharged product formed on the air cathode. The size of primary and secondary particles shown in Fig. 2 would also influence the charging voltage (i.e. voltage gap) corresponding to the decomposition of discharged products. Research on the effect of particle size on charging voltage is now in progress.

\section{Conclusions}

Li-air batteries with carbonate-based liquid electrolyte were constructed and their rechargeability at ambient temperature was evaluated. The cell was discharged and recharged for 100 cycles and high capacity retention of over $60 \%$ was achieved. On the other hand, a large voltage hysteresis of over $1.4 \mathrm{~V}$ was observed confirming the results reported so far. In order to find the reason for this voltage gap, discharged products on the air cathode surface were analyzed by TEM observation and FT-IR spectroscopy. From the results of such analyses, the ideal product, $\mathrm{Li}_{2} \mathrm{O}_{2}$ was not detected but lithium carbonate $\left(\mathrm{Li}_{2} \mathrm{CO}_{3}\right)$ and lithium alkylcarbonate $(\mathrm{RO}-(\mathrm{C}=\mathrm{O})-\mathrm{OLi})$ were obtained. These carbonate species were analogous in structure to carbonate solvents, suggesting that the solvents would be electrochemically decomposed under $\mathrm{O}_{2}$ atmosphere. It is, thus, concluded that the voltage gap between discharge and charge would be closely related with a side reaction due to the decomposed carbonate species, which is completely different from the ideal reaction, $2 \mathrm{Li}+\mathrm{O}_{2}=\mathrm{Li}_{2} \mathrm{O}_{2}$.

\section{References}

1) Handbook of Batteries and Fuel Cells, D. Linden, Editor, Chap. 30, McGraw-Hill, New York (1984).

2) H. Arai, Shigen-to-Sozai, 117, 177 (2001) [in Japanese].

3) K. M. Abraham and Z. Jiang, J. Electrochem. Soc., 143, 1 (1996).

4) J. Read, J. Electrochem. Soc., 149, A1190 (2002).

5) T. Kuboki, T. Okuyama, T. Ohsaki, and N. Takami, J. Power Sources, 146, 766 (2005).

6) T. Ogasawara, A. Debart, M. Holzapfel, P. Novak, and P. G. Bruce, J. Am. Chem. Soc., 128, 1390 (2006).

7) A. Debart, A. J. Paterson, J. L. Bao, G. Armstorng, and P. G. Bruce, Angew. Chem., Int. Ed., 47, 1 (2008).

8) S. D. Beattie, D. M. Manolescu, and S. L. Blair, J. Electrochem. Soc., 156, A44 (2009).

9) X.-H. Yang, P. He, and Y.-Y. Xia, Electrochem. Commun., 11, 1127 (2009).

10) M. Mirzaeian and P. J. Hall, Electrochim. Acta, 54, 7444 (2009).

11) W. Xu, J. Xiao, J. Zhang, D. Wang, and J.-G. Zhang, J. Electrochem. Soc., 156, A773 (2009).

12) D. Aurbach, M. Moshkovich, Y. Cohen, and A. Schechter, Langmuir, 15, 2947 (1999).

13) Y. Katayama, H. Onodera, M. Yamagata, and T. Miura, J. Electrochem. Soc., 151, A59 (2004). 